\title{
NITROGEN BALANCE, 3-METHYLHISTIDINE EXCRETION, AND PLASMA AMINO ACID PROFILE IN INFANTS AFTER CARDIAC OPERATIONS FOR CONGENITAL HEART DEFECTS: THE EFFECT OF EARLY NUTRITIONAL SUPPORT
}

\author{
Václav Chaloupecký, MD \\ Bohumil Hučín, MD \\ Tomáš Tláskal, MD \\ Martin Kostelka, MD ${ }^{a}$ \\ Vladimír Kučera, $\mathrm{MD}^{\mathrm{a}}$ \\ Jan Janoušek, MD \\ Jan Škovránek, MD \\ Luděk Šprongl, Ing ${ }^{\mathrm{b}}$
}

\begin{abstract}
Objective: The objective of this study was to evaluate the effect of nutritional support on proteolysis and plasma amino acid profile in infants early after cardiac operations for congenital heart defects. Methods: Thirty-seven patients, 2 to 12 months old, were randomized on postoperative day 1 for 24-hour isocaloric metabolic study. Group STANDARD (18 patients) received glucose as the maintenance fluid, and group $\mathrm{PN}$ (19 patients) received glucose and crystalloid amino acid solution at a dosage of $0.8 \pm 0.1$ $\mathrm{gm} / \mathrm{kg}$ per day. The nonprotein caloric intake in the two groups was $25 \pm 15$ and $33 \pm 9 \mathrm{kcal} / \mathrm{kg}$, respectively ( $p=$ not significant). Results: The nitrogen balance was markedly less negative in group PN than in group STANDARD $(-114 \pm 81 \mathrm{vs}-244 \pm 86 \mathrm{mg} / \mathrm{kg}$, respectively, $p=0.001)$. There was a highly significant inverse correlation between the nitrogen balance and urinary 3-methylhistidine excretion in both groups, but the muscle proteolysis was blunted more effectively in patients receiving amino acids. Concentrations of the plasmatic branched-chain amino acids, alanine, glycine, and proline, decreased significantly in group STANDARD but not in group PN on postoperative day 2 . Glutamine and threonine levels declined significantly on postoperative day 2 in both groups. Low levels of arginine were observed in our patients before operation and in the early postoperative period. The amino acid concentrations normalized on postoperative day 7 in all patients. Conclusion: Significant proteolysis and hypoaminoacidemia were observed in infants early after cardiac operations. This hypercatabolic response was blunted by parenteral nutritional support. (J Thorac Cardiovasc Surg 1997;114:1053-60)
\end{abstract}

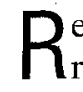
ecent medical progress allows us to successfully repair almost all congenital heart defects in the first months of life, but despite this spectacular progress in pediatric cardiac surgery, the postoperative morbidity in young infants is still higher than that in older children. ${ }^{1}$ The postoperative morbidity is affected by the combined effects of the generalized inflammatory reaction triggered by the contact be-

From Kardiocentrum ${ }^{\mathrm{a}}$ and the Department of Clinical Biochemistry, ${ }^{b}$ University Hospital Motol, Prague, Czech Republic.

Supported by the Grant Agency of the Czech Ministry of Health, grant No. 2043-3.

Received for publication Júly 31, 1996; revisions requested Sept. 16, 1996; revisions received June 10, 1997; accepted for publication June 12; 1997.

Address for reprints: Václav Chaloupecký, MD, Kardiocentrum, University Hospital Motol, Vúvalu 84, 15006 Prague 5, Czech Republic.

Copyright $(\mathcal{C} 1997$ by Mosby-Year Book, Inc.

$0022-5223 / 97 \$ 5.00+0 \quad$ i2/i/83907 tween blood and the foreign surfaces of the cardiopulmonary bypass unit ${ }^{1-4}$ and the hypercatabolic response to stress and trauma in the perioperative period..$^{5}$ An increased microvascular permeability and hypoproteinemia caused by extensive proteolysis and decreased hepatic albumin synthesis contribute to edema formation and secondary organ dysfunction even in children after complete repair and in the presence of good hemodynamic performance.

Protein metabolism in infants after cardiac operations has not been studied extensively even though severe undernutrition was observed in one study in more than half the children with congenital heart defects. ${ }^{6}$ This is of clinical importance because failure to thrive was a major factor associated with increased postoperative morbidity, increased hospital costs, and a prolonged hospital stay in patients after operations for congenital heart disease.

We have undertaken a prospective study to determine the extent of proteolysis and plasma amino 
Table I. Diagnosis and surgical repairs

\begin{tabular}{|c|c|c|}
\hline Diagnosis & Procedure & Patients \\
\hline Ventricular septal defect & Patch repair & 14 \\
\hline $\begin{array}{l}\text { Transposition of the great } \\
\text { arteries }\end{array}$ & $\begin{array}{l}\text { Senning } \\
\text { procedure }\end{array}$ & 9 \\
\hline Atrioventricular septal defect & $\begin{array}{l}\text { Double patch } \\
\text { repair }\end{array}$ & 5 \\
\hline Double-outlet right ventricle & Correction & 2 \\
\hline $\begin{array}{l}\text { Anomalous origin of the left } \\
\text { coronary artery from the } \\
\text { pulmonary artery }\end{array}$ & $\begin{array}{l}\text { Takeushi } \\
\text { procedure }\end{array}$ & 1 \\
\hline Truncus arteriosus & Homograft & 1 \\
\hline Atrial septal defect & Patch repair & 1 \\
\hline Cor triatriatum & Correction & 1 \\
\hline Hemitruncus & Correction & 1 \\
\hline Tetralogy of Fallot & Correction & 1 \\
\hline $\begin{array}{l}\text { Total anomalous pulmonary } \\
\text { verious connection }\end{array}$ & Correction & 1 \\
\hline Total & & 37 \\
\hline
\end{tabular}

acid profile abnormalities in infants after operations for congenital heart defects. A randomized trial was done to evaluate the effect of nutritional support on the hypercatabolic reaction in the early postoperative period.

\section{Patients and methods}

The protocol of the study was approved by the Ethical Committee of the University Hospital Motol. Thirty-seven infants, 2 to 12 months old (mean $6.7 \pm 3.4$ months), operated on to correct congenital heart defects with the use of cardiopulmonary bypass were entered into the prospective metabolic balance study. The body weight of the infants ranged from 3.0 to $9.8 \mathrm{~kg}$ (mean $5.9 \pm 1.9 \mathrm{~kg}$ ) and the corrected body weight ( $\mathrm{Z}$ value) from -4.0 to -0.5 (mean $-2.4 \pm 1.0$ ) of the standard deviation for agematched, normal, healthy Czech children. The diagnoses and surgical repairs undertaken are listed in Table I.

The operations were done with extracorporeal circulation and deep hypothermia with low flow or circulatory arrest. The extracorporeal circuit consisted of a Stöckert roller pump and a hollow-fiber oxygenator (Capiox 308, Terumo, or Masterflo D 701, Dideco) or a bubble oxygenator (Bentley Bio 2, Baxter) with a total priming volume of approximately $500 \mathrm{ml}$. The pump circuit was filled with a Ringer's solution with heparin, mannitol, and fresh blood to achieve a perfusate hematocrit value of about 0.25 . The total bypass time ranged from 28 to 220 minutes (mean $88 \pm 37$ minutes) and the duration of ischemia (achieved with cold crystalloid cardioplegic solution) was from 9 to 97 minutes (mean $48 \pm 20$ minutes).

Postoperative care. The following parameters were monitored continuously (Sirecust 1260, Siemens): systemic arterial pressure, central venous pressure, left atrial pressure, electrocardiogram, and rectal and peripheral temperatures. All patients received mechanical ventilation (BP 2001 Bear or Servoventilator 900C, Siemens) and sedation with morphine.
Table II. Composition of the crystalloid amino acid solution Nutramin P 8\%

\begin{tabular}{lcc}
\multicolumn{1}{c}{ Amino acid } & Abbreviations & gm/L \\
\hline L-Valine & val & 6.80 \\
L-Leucine & leu & 9.54 \\
L-Isoleucine & ile & 6.20 \\
L-Phenylalanine & phe & 3.48 \\
L-Methionine & met & 2.20 \\
L-Lysine & lys & 6.10 \\
L-Threonine & thr & 4.10 \\
L-Tryptophan & trp & 1.20 \\
L-Arginine & arg & 8.30 \\
L-Histidine & his & 2.00 \\
L-Alanine & ala & 4.10 \\
L-Glutamic acid & glu & 8.10 \\
L-Aspartic acid & asp & 2.50 \\
L-Proline & pro & 6.80 \\
L-Serine & ser & 3.30 \\
Glycine & gly & 1.50 \\
L-Cysteine & cys & 0.37 \\
N-Acetyl-L-tyrosine & tyr & 3.54 \\
- & & \\
\hline
\end{tabular}

Total fluid intake including all maintenance fluids, drugs, and flushing volumes for arterial and venous catheters was restricted on the day of the operation (day 0) to $50 \mathrm{ml} / \mathrm{kg}$ per day and on the first postoperative day (day 1) to $75 \mathrm{ml} / \mathrm{kg}$ per day. Ten percent glucose was used as the basic solution for dilution of catecholamines and $\mathrm{KCl}$ supplements. The arterial catheter was flushed (Deltran II, $3 \mathrm{ml} / \mathrm{hr}$ ) with normal saline solution and heparin. A Foley catheter was used to allow hourly measurements of urine output. Urine was collected for 24 hours for the determination of levels of electrolytes and urea and of 3-methylhistidine losses.

Protocol of the study. The 24-hour metabolic balance study started at 6 am on the first postoperative day (day 1) and ended at $6 \mathrm{am}$ on the second postoperative day (day 2). The patients were randomized either to group STANDARD with a normal fluid regimen or to group PN with an early parenteral nutritional support regimen that used a pediatric amino acid solution. The planned total fluid intake was restricted to $75 \mathrm{ml} / \mathrm{kg}$ per day and glucose intake was adjusted to approximately $5.0 \mathrm{mg} / \mathrm{kg}$ per minute in both groups. Patients in group STANDARD received as the maintenance fluid $10 \%$ glucose, whereas patients in group PN received $10 \%$ to $20 \%$ glucose and a commercially available pediatric amino acid solution (Nutramin P $8 \%$, Spofa) at a planned dosage of $1.0 \mathrm{gm} / \mathrm{kg}$ per day of amino acids. The amino acid composition of Nutramin P amino acid solution is shown in Table II. The parenteral nutritional support was withdrawn in group $P N$ and enteral feeding was gradually reintroduced on postoperative day 2 in both groups. All patients received a full-strength infant formula by postoperative day 7 .

Blood sampling. Blood samples for determining the concentrations of amino acids and for standard biochemical and hematologic testing were taken after the induction of anesthesia and each morning on postoperative days 1,2 , and 7 . 
Table III. Clinical data

\begin{tabular}{|c|c|c|c|}
\hline & $\begin{array}{l}\text { Group PN } \\
(N=19)\end{array}$ & $\begin{array}{c}\text { Group } \\
\text { STANDARD } \\
(N=18)\end{array}$ & $p$ Value \\
\hline Age (mo) & $6.0 \pm 3.2$ & $8.1 \pm 3.4$ & NS \\
\hline Body weight (kg) & $5.5 \pm 2.0$ & $6.3 \pm 1.7$ & NS \\
\hline $\begin{array}{l}\text { Corrected body weight } \\
\text { ( } Z \text { value) }\end{array}$ & $-2.5 \pm 1.1$ & $-2.2 \pm 0.9$ & NS \\
\hline Bypass time (min) & $88 \pm 27$ & $90 \pm 46$ & NS \\
\hline $\begin{array}{l}\text { Aortic crossclamping } \\
\text { time (min) }\end{array}$ & $51 \pm 18$ & $46 \pm 21$ & NS \\
\hline Intubation (days) & $2.7 \pm 2.3$ & $2.6 \pm 1.7$ & NS \\
\hline $\begin{array}{l}\text { Inotropic support } \\
\text { (days) }\end{array}$ & $2.1 \pm 0.2$ & $2.3 \pm 0.9$ & NS \\
\hline
\end{tabular}

Values are given as mean plus or minus the standard deviation. NS, Not significant.

Biochemical analysis. The levels of plasma amino acids and 3-methylhistidine in the urine were measured by the chromatographic method on an automatic amino acid analyzer (AAA 339 M, Mikrotechna Praha) after deproteinization with sulfosalicylic acid. The standard biochemical tests were done on an automatic analyzer (Monarch 2000, Instrumentation Laboratories, Inc., Watertown, Mass.). The total urinary nitrogen level was estimated by multiplying the urinary urea content by a factor of 1.2.

Calculations and statistics. The body weight of the patients in the study and individual plasma amino acid concentrations were compared with those of normal agematched infants by the $Z$-value method according to the equation $Z=\left(v-v_{n}\right) / S D_{n}$, where $v$ is the observed value and $v_{n}$ and $S D_{n}$ are the average and standard deviation of the normal population. Sigma Stat (Jandel Corporation) statistical software was used. The time course comparisons within groups were done with one-way repeatedmeasure analysis of variance. When overall significance was found a $t$ test for paired samples was used. The differences between the two groups were compared by unpaired $t$ test. All samples were tested for normality and parametric or nonparametric tests were used where appropriate. Results are expressed as mean and standard deviation. Significance was accepted at $p<0.05$.

\section{Results}

Clinical data. All patients survived and were discharged from the hospital. Twenty-eight (76\%) patients were extubated within 72 hours after the operation and the remaining nine patients were extubated between postoperative days 4 and 9 . The continuous infusion of catecholamines was discontinued in all patients within 4 days (median 2 days) after the operation.

Nineteen infants were allocated to group PN and 18 infants to group STANDARD. The relevant clinical data are summarized in Table III. There was no difference between the groups regarding age,
Table IV. Total fluids, glucose, nonprotein calories, and amino acid intake on postoperative day 1

\begin{tabular}{lccc} 
& \multicolumn{3}{c}{ Group } \\
& Group PN & STANDARD & p Value \\
\hline Fluids $(\mathrm{ml} / \mathrm{kg})$ & $83 \pm 14$ & $73 \pm 18$ & NS \\
Glucose $(\mathrm{mg} / \mathrm{kg} / \mathrm{min})$ & $5.6 \pm 1.5$ & $4.2 \pm 2.6$ & NS \\
Nonprotein calories & $33 \pm 9$ & $25 \pm 15$ & NS \\
$\quad$ (kcal $/ \mathrm{kg})$ & & & \\
Amino acids (gm $/ \mathrm{kg})$ & $0.8 \pm 0.1$ & - & \\
\hline
\end{tabular}

Values are given as mean plus or minus the standard deviation. NS, Not significant.

body weight, bypass time, or aortic crossclamping time. The corrected body weight ( $\mathrm{Z}$ value) was lower than -2.0 standard deviations of the body weight of the normal population in both groups. The postoperative morbidity evaluated as the total intubation time and inotropic support requirement was similar in both groups (Table III). There were no severe complications such as low cardiac output syndrome, renal failure, or sepsis in our patients. Nine patients required prolonged artificial ventilation because of fluid retention and increased tracheobronchial secretions irrespective of the mode of nutritional support.

The total fluids, glucose, and nonprotein caloric intake received on the first postoperative day (day 1) was similar in both groups (Table IV). The patients in group PN received $0.8 \pm 0.1 \mathrm{gm} / \mathrm{kg}$ per day of amino acids, that is, $112 \pm 20 \mathrm{mg} / \mathrm{kg}$ per day of nitrogen. There was no difference between the groups regarding serum urea or blood glucose concentration.

Nitrogen balance and 3-methylhistidine excretion. The nitrogen losses, 3-methylhistidine excretion, and 3-methylhistidine/creatinine ratio in urine were higher on postoperative day 1 in group STANDARD than in group PN infants, but the difference was not significant (Table V).

The nitrogen balance was markedly less negative in patients in group $\mathrm{PN}$ at $-114 \pm 81 \mathrm{mg} / \mathrm{kg}$ than in group STANDARD at $-244 \pm 86 \mathrm{mg} / \mathrm{kg}(p=0.001)$ during the measurement period on postoperative day 1 . There was a highly significant inverse correlation between the nitrogen balance and urinary 3-methylhistidine excretion in both groups (Fig. 1).

Plasma amino acids. The changes in plasma amino acid concentrations are shown in Table VI. Compared with preoperative values the branchedchain amino acids (BCAA: valine, leucine, isoleucine), alanine, glycine, and proline values decreased 


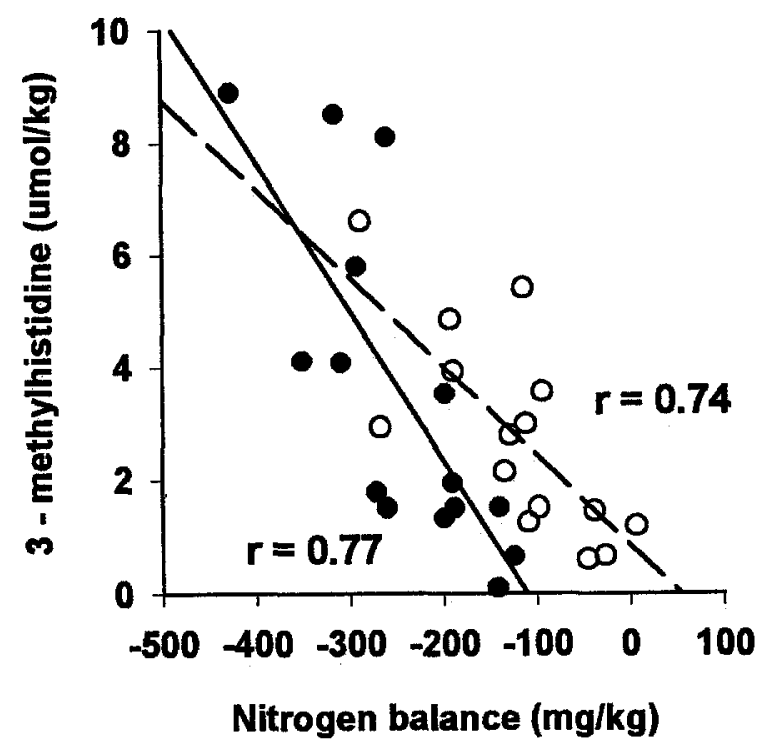

Fig. 1. Regression between nitrogen balance and 3-methylhistidine excretion during the first postoperative day. For group $\mathrm{PN}$, patients receiving early nutritional support (open circles, dashed line), the graph shows 3-methylhistidine $=0.864-0.0158 \times$ nitrogen balance $(p=0.002)$; for group STANDARD, patients receiving standard fluid protocol (closed circles, solid line), the graph shows 3methylhistidine $=-2.92-0.0265 \times$ nitrogen balance $(p=$ 0.001 ).

significantly in group STANDARD but not in group PN at the end of the study on postoperative day 2, whereas values of glutamine and threonine declined significantly in both groups. The plasma amino acid concentrations normalized by postoperative day 7 in all patients.

The BCAA to aromatic amino acid (AAA: phenylalanine plus tyrosine) ratio (Fig. 2) was reduced in the early postoperative period in both groups. However, the BCAA/AAA ratio was significantly lower in group STANDARD than in group PN at the end of the study on postoperative day 2 .

Fig. 3 demonstrates the relative changes ( $Z$ value) in plasma amino acid concentrations compared with reported normal values. ${ }^{8}$ The preoperative amino acid profile in infants with congenital heart defects was in general similar to that of healthy children. The early postoperative period (day 1 and day 2) was characterized by decreased BCAA and glutamine levels and increased phenylalanine plasma levels. Plasma arginine concentrations were low in our patients before operation and during the first 2 days after the operation.
Table V. Diuresis and 3-methylhistidine and urinary nitrogen excretion on postoperative day 1

\begin{tabular}{lccc}
\hline & \multicolumn{3}{c}{ Group } \\
& Group PN & STANDARD & $p$ Value \\
\hline Diuresis $(\mathrm{ml} / \mathrm{kg})$ & $56 \pm 25$ & $59 \pm 25$ & NS \\
Nitrogen $(\mathrm{mg} / \mathrm{kg})$ & $225 \pm 80$ & $244 \pm 86$ & NS \\
$3 \mathrm{mHIS}(\mu \mathrm{mol} / \mathrm{kg})$ & $2.6 \pm 1.8$ & $3.5 \pm 2.8$ & NS \\
$3 \mathrm{mHIS} / \mathrm{Cr}(\mu \mathrm{mol} / \mathrm{gm})$ & $259 \pm 166$ & $289 \pm 167$ & NS
\end{tabular}

Values given as mean plus or minus the standard deviation. $3 m H I S$, 3-Methylhistidine; $N S$, not significant; $3 m H I S / C r$, 3-methylhistidine/creatinine ratio.

\section{Discussion}

Nitrogen balance and 3-methylhistidine excretion. We have studied the effects of early parenteral administration of a balanced pediatric amino acid solution on overall proteolysis and muscle protein breakdown by measuring urinary nitrogen losses and 3-methylhistidine excretion. The metabolic response to stress and trauma in infants early after cardiac operations was significant. The urinary nitrogen losses observed in our study during the first postoperative day were increased to levels observed in patients after severe injury or sepsis. ${ }^{9}$ 3-Methylhistidine excretion, a unique marker of muscle proteolysis, was in our patients, corrected per body muscle mass (urinary 3-methylhistidine/creatinine ratio), about three times higher than values reported for healthy subjects. ${ }^{10,11}$

The nitrogen balance on postoperative day 1 was markedly less negative in infants with amino acid supplementation than in infants receiving the usual fluid regimen. We also documented a highly significant inverse correlation between the 3-methylhistidine excretion and the daily nitrogen balance indicating an association between nitrogen retention and reduction in muscle proteolysis as observed in other patients with hypercatabolism. ${ }^{11-13}$ The considerable variation in 3-methylhistidine excretion in our patients corresponded to the individual response to trauma and stress in the postoperative period. However, the less steep slope of the linear correlation curve in infants in group PN suggested that nutritional support with use of the amino acid solution blunted the muscle proteolysis more effectively than glucose alone.

Plasma amino acids. The changes in amino acid metabolism after cardiac operations have been, to our knowledge, studied only in adults. ${ }^{14-17}$ We have observed in infants transiently but significantly decreased plasmatic BCAA, glutamine, alanine, glycine, threonine, proline, and arginine levels and 
Table VI. Plasma amino acid concentrations

\begin{tabular}{|c|c|c|c|c|c|c|}
\hline & Preop. & Day 1 & Day 2 & Day 7 & $F$ value & $p$ Value \\
\hline \multirow[t]{2}{*}{ L-Aspartic acid } & $11.9 \pm 6.5^{*}$ & $23.6 \pm 17.5 \dagger$ & $17.7 \pm 11.2 \dagger$ & $13.8 \pm 8.5$ & 5.23 & 0.004 \\
\hline & $18.6 \pm 13.0$ & $13.5 \pm 12.2$ & $12.8 \pm 7.6$ & $20.6 \pm 16.8$ & 2.41 & NS \\
\hline \multirow[t]{2}{*}{ L-Glutamic acid } & $72.4 \pm 30.7$ & $73.7 \pm 41.4$ & $60.2 \pm 23.9$ & $65.5 \pm 22.1$ & 1.13 & NS \\
\hline & $68.8 \pm 41.5$ & $61.4 \pm 33.7$ & $44.6 \pm 22.4$ & $65.9 \pm 25.2$ & 1.68 & NS \\
\hline \multirow[t]{2}{*}{ L-Arginine } & $33.9 \pm 13.0$ & $19.2 \pm 10.9 \dagger$ & $30.8 \pm 15.8$ & $46.6 \pm 28.2$ & 7.66 & 0.001 \\
\hline & $33.5 \pm 13.4$ & $24.4 \pm 11.9$ & $24.5 \pm 9.9$ & $42.2 \pm 19.2$ & 4.65 & 0.008 \\
\hline \multirow{2}{*}{ L-Lysine } & $89.6 \pm 31.8$ & $67.3 \pm 27.1 \dagger$ & $79.7 \pm 30.4$ & $135.5 \pm 84.3$ & 8.21 & 0.001 \\
\hline & $90.6 \pm 32.9$ & $73.5 \pm 31.1 \dagger$ & $73.5 \pm 30.5$ & $138.5 \pm 78.3$ & 9.24 & 0.001 \\
\hline \multirow[t]{2}{*}{ L-Histidine } & $59.9 \pm 18.2$ & $59.0 \pm 24.6$ & $65.1 \pm 30.5$ & $77.9 \pm 47.8$ & 1.18 & NS \\
\hline & $63.2 \pm 23.6$ & $63.3 \pm 22.0$ & $54.5 \pm 24.1$ & $73.4 \pm 33.1$ & 0.82 & NS \\
\hline \multirow[t]{2}{*}{ L-Glutamine } & $409.2 \pm 105.6$ & $324.2 \pm 113.4 \dagger$ & $278.3 \pm 95.5 \dagger$ & $397.4 \pm 204.5$ & 3.63 & 0.020 \\
\hline & $401.8 \pm 134.4$ & $384.8 \pm 148.6$ & $287.6 \pm 86.4 \dagger$ & $479.0 \pm 175.9$ & 8.67 & 0.001 \\
\hline \multirow[t]{2}{*}{ L-Alanine } & $199.5 \pm 52.3$ & $175.4 \pm 96.5$ & $188.6 \pm 101.4$ & $195.8 \pm 88.0$ & 0.66 & NS \\
\hline & $176.3 \pm 61.8$ & $193.1 \pm 96.9$ & $128.9 \pm 55.2 \dagger$ & $207.4 \pm 59.5$ & 5.06 & 0.005 \\
\hline \multirow[t]{2}{*}{ L-Isoleucine } & $39.3 \pm 11.3$ & $31.0 \pm 21.0$ & $35.1 \pm 11.7$ & $40.0 \pm 16.1$ & 1.76 & NS \\
\hline & $38.1 \pm 13.1$ & $34.2 \pm 21.8$ & $23.7 \pm 23.7+t$ & $54.9 \pm 29.4$ & 6.91 & 0.001 \\
\hline \multirow[t]{2}{*}{ L-Valine } & $137.8 \pm 43.1$ & $123.8 \pm 60.7$ & $130.1 \pm 38.1$ & $144.5 \pm 66.0$ & 0.51 & NS \\
\hline & $136.2 \pm 41.1$ & $127.7 \pm 55.2$ & $90.6 \pm 35.0+t$ & $169.1 \pm 56.4$ & 7.60 & 0.001 \\
\hline \multirow[t]{2}{*}{ L-Leucine } & $73.9 \pm 18.2$ & $63.9 \pm 18.0$ & $68.4 \pm 20.2$ & $88.3 \pm 33.3$ & 3.44 & 0.024 \\
\hline & $73.1 \pm 22.5$ & $77.3 \pm 38.4$ & $47.6 \pm 17.7+\neq$ & $108.8 \pm 56.0$ & 6.77 & 0.001 \\
\hline \multirow{2}{*}{ L-Glycine } & $146.2 \pm 43.4$ & $157.1 \pm 77.2$ & $127.1 \pm 44.6$ & $133.3 \pm 46.7$ & 1.57 & NS \\
\hline & $147.4 \pm 53.1$ & $141.2 \pm 50.1$ & $119.1 \pm 34.1 \dagger$ & $175.6 \pm 55.8$ & 3.98 & 0.014 \\
\hline \multirow[t]{2}{*}{ L-Proline } & $132.2 \pm 42.4$ & $86.9 \pm 34.2 \dagger$ & $100.1 \pm 32.1$ & $206.4 \pm 82.2$ & 18.8 & 0.001 \\
\hline & $110.4 \pm 42.2$ & $90.4 \pm 37.9$ & $67.7 \pm 27.6+t$ & $127.2 \pm 30.5$ & 14.8 & 0.001 \\
\hline \multirow[t]{2}{*}{ L-Phenylalanine } & $50.0 \pm 19.3$ & $63.7 \pm 24.0 \dagger$ & $73.3 \pm 26.0 \dagger$ & $52.5 \pm 23.2$ & 6.67 & 0.001 \\
\hline & $49.0 \pm 17.6$ & $67.2 \pm 24.5 \dagger$ & $63.4 \pm 23.2$ & $61.7 \pm 25.4$ & 3.49 & 0.024 \\
\hline \multirow{2}{*}{$N$-Acetyl-L-tyrosine } & $57.4 \pm 20.1$ & $54.7 \pm 21.9$ & $50.4 \pm 17.0$ & $71.1 \pm 32.2$ & 5.17 & 0.004 \\
\hline & $53.4 \pm 16.1$ & $57.9 \pm 23.9$ & $42.7 \pm 13.9$ & $79.9 \pm 39.4$ & 7.35 & 0.001 \\
\hline \multirow[t]{2}{*}{ L-Tryptophan } & $20.7 \pm 10.0$ & $24.1 \pm 9.6$ & $26.1 \pm 15.5$ & $16.1 \pm 12.0$ & 1.57 & NS \\
\hline & $23.3 \pm 10.6$ & $28.4 \pm 13.3$ & $19.9 \pm 17.4$ & $35.1 \pm 20.2$ & 1.71 & NS \\
\hline \multirow[t]{2}{*}{ L-Serine } & $93.3 \pm 29.8$ & $75.1 \pm 47.2$ & $73.8 \pm 31.1 \dagger$ & $90.1 \pm 21.7$ & 2.44 & NS \\
\hline & $87.8 \pm 38.6$ & $71.0 \pm 26.0$ & $67.7 \pm 20.9$ & $108.8 \pm 47.7$ & 7.91 & 0.005 \\
\hline \multirow[t]{2}{*}{ L-Threonine } & $76.6 \pm 31.7$ & $55.3 \pm 28.6$ & $55.4 \pm 20.3 \dagger$ & $102.3 \pm 60.3$ & 6.30 & 0.001 \\
\hline & $64.1 \pm 37.9$ & $53.6 \pm 24.8 \dagger$ & $43.6 \pm 15.5+\neq$ & $122.1 \pm 67.1$ & 12.8 & 0.001 \\
\hline \multirow[t]{2}{*}{ L-Cysteine } & $55.4 \pm 13.8$ & $31.4 \pm 16.9 \dagger$ & $41.1 \pm 17.5 \dagger$ & $62.8 \pm 27.4$ & 7.01 & 0.001 \\
\hline & $46.4 \pm 15.9$ & $39.0 \pm 14.5 \uparrow$ & $37.2 \pm 13.6$ & $58.0 \pm 17.5$ & 6.57 & 0.001 \\
\hline \multirow[t]{2}{*}{ L-Methionine } & $18.0 \pm 6.3$ & $14.4 \pm 6.0$ & $17.2 \pm 6.1$ & $20.9 \pm 11.3$ & 1.71 & NS \\
\hline & $15.2 \pm 6.6$ & $15.7 \pm 7.4$ & $11.7 \pm 5.9$ & $23.5 \pm 13.3$ & 3.97 & 0.014 \\
\hline \multirow[t]{2}{*}{ L-Taurine } & $49.4 \pm 35.2$ & $44.6 \pm 35.4$ & $51.9 \pm 39.5$ & $59.5 \pm 40.0$ & 1.27 & NS \\
\hline & $54.2 \pm 42.3$ & $49.6 \pm 28.5$ & $59.6 \pm 30.1$ & $60.1 \pm 47.9$ & 0.39 & NS \\
\hline
\end{tabular}

Values are given as mean plus or minus the standard deviation. NS, Not significant.

*Top numbers are for group PN; bottom numbers are for group STANDARD.

fp $<0.05$ between group PN and group STANDARD.

elevated phenylalanine levels in the early postoperative period. Stress and trauma cause an extensive muscle proteolysis with a resultant release of amino acids into the plasma for oxidative metabolism and for the protein synthesis involved in the immune reactions, healing, and vital organs function. ${ }^{5}$ Both main factors responsible for muscle proteolysis, increased levels of the major stress hormones (epinephrine, cortisol, and gluca- gon $)^{2,18,19}$ and activated cytokine mediators, ${ }^{3,4}$ have been documented in patients after cardiac operations.

The decrease of some plasma amino acids in our study indicated a mismatch between their endogenic supply and increased demands in infants early after cardiac operations. Because the skeletal muscle has been recognized as the principal source of BCAAs, glutamine, and alanine in adults after cardiac oper- 


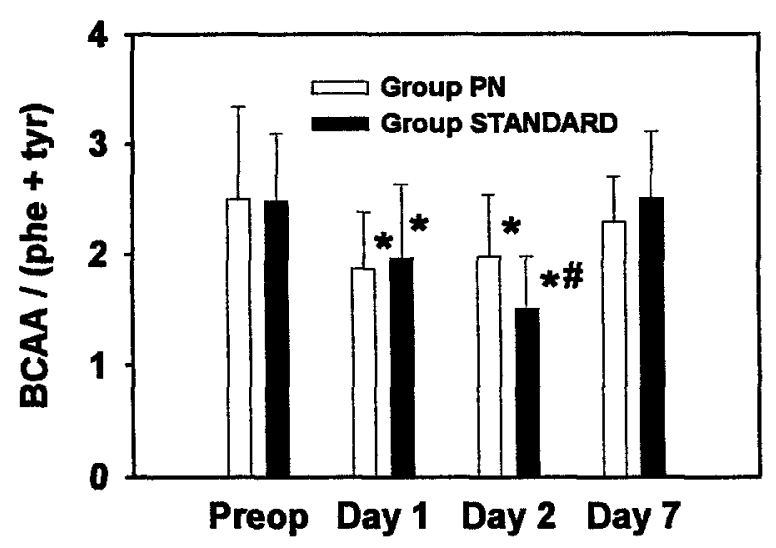

Fig. 2. The BCAA/AAA (phenylalanine plus tyrosine $[p h e+t y r])$ ratio. ${ }^{*} p<0.05$ versus preoperative values; ${ }^{\#} p<0.05$ between patients receiving the standard fluid protocol (group STANDARD) and patients receiving early nutritional support (group PN).

ations, ${ }^{15}$ it is probable that infants with congenital heart defects and dystrophy have a limited endogenous pool of amino acids. Reduced BCAA/AAA ratios observed in our patients also suggest an increased clearance of BCAA and impaired hepatic uptake of AAAs as in other critically ill patients. ${ }^{5}$

The clinical consequence of hypoaminoacidemia in infants early after cardiac operations remains to be established, but we have demonstrated that except for the level of glutamine this can be blunted by amino acid supplementation. The Nutramin P $8 \%$, Spofa, used in our study is a commercially available glutamine-free pediatric amino acid solution with an increased concentration of BCAAs (28.2\%), glutamate $(10 \%)$, and proline $(8.5 \%)$. The decline in plasma glutamine levels in infants early after the cardiac operation was alarming. Glutamine is the key amino acid for the metabolism of intestinal tract, renal tubular cells, endothelial cells, and the immune system. ${ }^{20}$ Although glutamine is the most abundant amino acid in the human body it becomes an indispensable nutritional component in the critically ill patient. ${ }^{20}$ Unfortunately, because of its rapid disintegration in water glutamine is not available in commercial amino acid solutions for parenteral administration.

The BCAAs are a crucial metabolic substrate for patients with hypercatabolism, particularly in sepsis and hepatic failure. ${ }^{5}$ Although the normal heart extracts only a small amount of amino acids, during ischemia and reperfusion the BCAAs and glutamate are important substrates for myocardial energy metabolism and protein synthesis, ${ }^{15-17}$ particularly in the immature heart. ${ }^{21}$

Low plasma arginine levels were observed in our patients preoperatively and early after operation. Because nitric oxide is synthesized from L-arginine, the low arginine levels may be important for infants with an increased pulmonary vascular reactivity in the early postoperative period, but the clinical significance of this interesting observation is not known. It was demonstrated that both systemic and pulmonary vascular resistance decreased in critically ill patients after intravenous L-arginine administration. ${ }^{22}$ Moreover, the beneficial effects of $\mathrm{L}$-arginine after hypothermic ischemia and reperfusion in neonatal hearts were confirmed. ${ }^{23}$

Clinical outcome. We have confirmed in our study the presence of an extensive proteolysis and significant hypoaminoacidemia early after cardiac operations in infants with limited metabolic reserves. Parenteral amino acid administration on the first postoperative day blunted the proteolysis more effectively than glucose alone, but the higher caloric intake in group PN, although it was not significant, could have been also influential. The plasma amino acid profile normalized within 1 week after the operation in our selected group of patients with uncomplicated recovery. Therefore parenteral amino acid supplementation is not necessary in infants with normal postoperative convalescence in whom early enteral nutrition is emphasized.

On the other hand, we would strongly recommend parenteral nutritional support in stressed infants with severe circulatory failure and other complications such as capillary leak, renal failure, and sepsis that are usually followed by gastrointestinal subsystem dysfunction. However, parenteral nutrition in infants early after cardiac operations presents some specific problems. The usual fluid protocol used in infants, ${ }^{24}$ because of necessary volume restriction, covers only about $50 \%$ of the measured energy expenditure, according to data published by Gebara, Gelmini, and Sarnaik ${ }^{25}$ in children early after operation for congenital heart defects. The substrate utilization in the same study also showed a shift toward fat oxidation and either gluconeogenesis or impaired carbohydrate utilization. The role of intravenous lipid emulsions in children early after cardiac operations remains to be clarified because of their rather unpredictable pharmacologic effects on the pulmonary vascular reactivity, lung function, and 


\section{Preop}

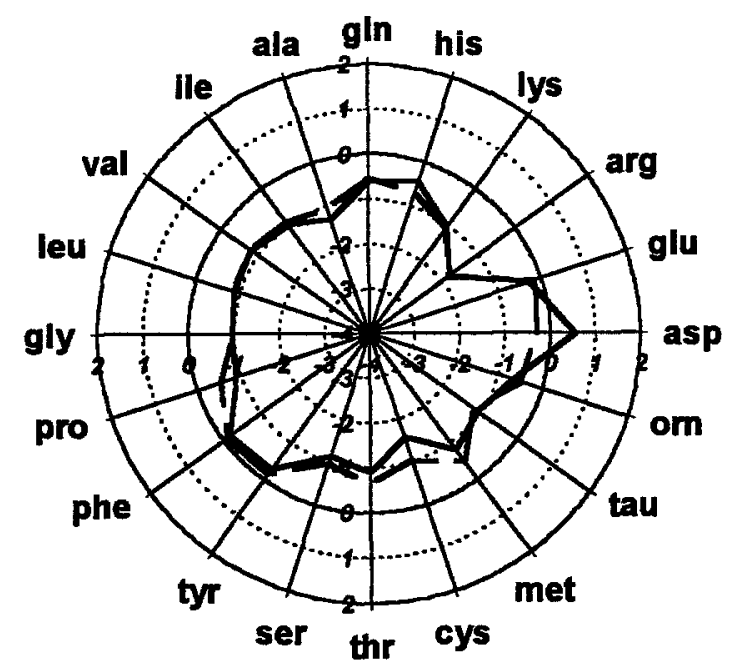

Day 2

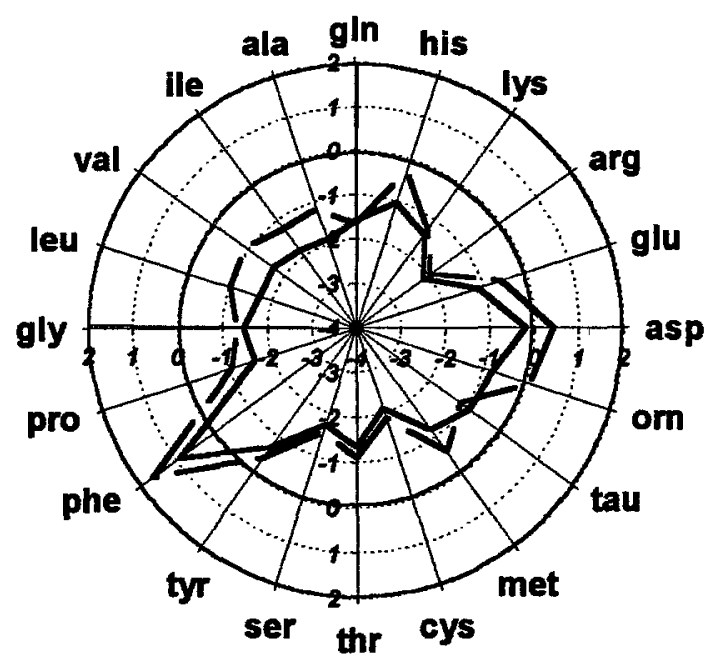

Day 1

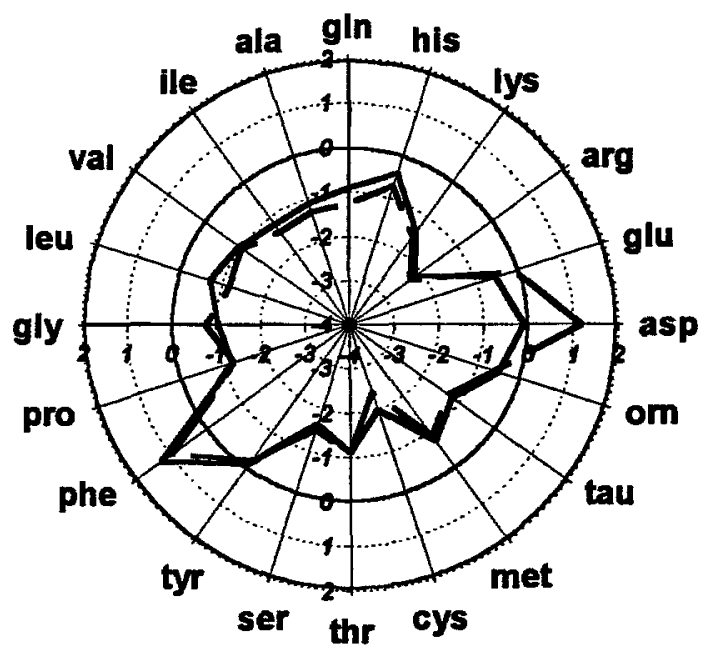

Day 7

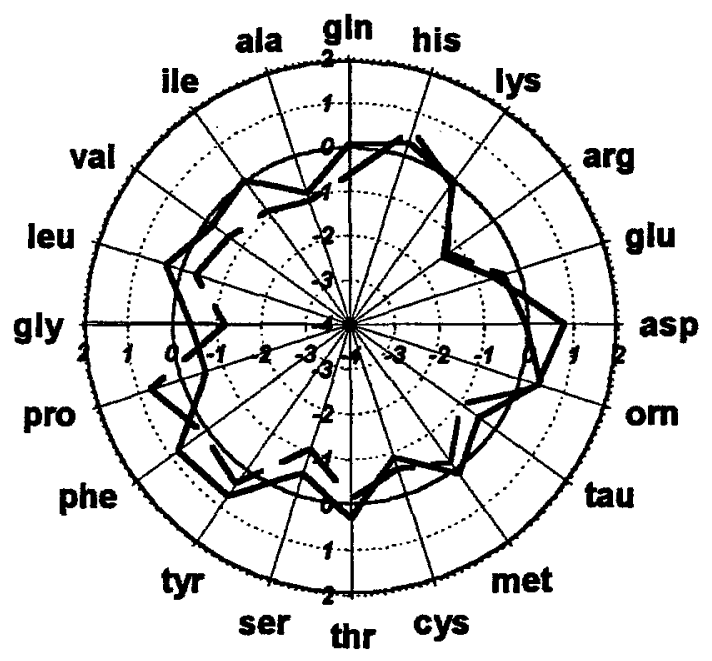

Fig. 3. The relative mean plasma amino acid concentrations ( $Z$ values) with regard to reported normal values. The solid circle equals zero standard deviation from the control group. Each dotted circle represents the difference of one standard deviation from the mean of the normal values. Group PN, patients receiving early nutritional support, is indicated by the dashed line; group STANDARD, patients receiving standard fluid protocol, is indicated by the solid line. Gln, Glutamine; tau, L-taurine; om, L-ornithine. Other abbreviations as in Table II.

immune response in critically ill patients. ${ }^{26}$ Therefore amino acids are an essential metabolic fuel in children with hypercatabolism early after cardiac operations and, even more notably, they may have important but yet not fully understood pharmacologic effects in patients with unstable circulation.
Conclusion. Extensive muscle proteolysis and hypoaminoacidemia were confirmed in infants early after cardiac operations for congenital heart defects. This hypercatabolic response was blunted by parenteral nutritional support. Intravenous amino acid administration should be considered in the complex 
treatment of children stressed by a complicated postoperative course and gastrointestinal system dysfunction.

\section{REFERENCES}

1. Kirklin JK. Prospects for understanding and eliminating the deleterious effects of cardiopulmonary bypass. Ann Thorac Surg 1991;51:529-31.

2. Downing SW, Edmunds LH Jr. Release of vasoactive substances during cardiopulmonary bypass. Ann Thorac Surg 1992;54:1236-43.

3. Butler J, Rocker GM, Westaby S. Inflammatory response to cardiopulmonary bypass. Ann Thorac Surg 1993;55:552-9.

4. Butler J, Pathi VL, Paton RD, et al. Acute-phase responses to cardiopulmonary bypass in children weighing less than 10 kilograms. Ann Thorac Surg 1996;62:538-42.

5. Siegel JH, Goodzari S, Gaudelupi P, et al. The host defense to trauma and sepsis: multiple organ failure as a manifestation of host defense failure disease. In: Schlag G, Redl H, editors. Pathophysiology of shock, sepsis, and organ failure. Berlin, Heidelberg, New York: Springer-Verlag; 1993. p. 627-64.

6. Mitchell IM, Logan RW, Pollock JCS, Jamieson MPG. Nutritional status of children with congenital heart disease. Br Heart J 1995;73:277-83.

7. Silberbach M, Shumaker D, Menashe V, Cobanoglu A, Morris C. Predicting hospital charge and length of stay for congenital heart disease surgery. Am J Cardiol 1993;72:958-63.

8. Liappis N, Gobien N, Schlebusch H. Referenzwerte fur die Konzentration der freien Aminosauren im Nuchternserum von Kindern. Klin Padiatr 1990;202:161-7.

9. Iapichino G, Radrizzani D. Anabolic drive in critically ill patients: pros and cons of a prevailing glucose system. In; Wilmore DW, Carpentier YA, editors. Metabolic support of the critically ill patient. 1st ed. Berlin, Heidelberg: SpringerVerlag; 1993. p. 137-56.

10. Lukaski HC, Mendez J, Bushkirk ER, Cohn SH. Relationship between endogenous 3-methylhistidine excretion and body composition. Am J Physiol 1981;240:E302-7.

11. Seashore JH, Huszar GB, Davis EM. Urinary 3-methylhistidine excretion and nitrogen balance in healthy and stressed premature infants. J Pediatr Surg 1980;15:400-4.

12. Radrizzani D, Iaipichino G, Cambisano M, Bonetti G, Ronzoni G, Colombo A. Peripheral, visceral and body nitrogen balance of catabolic patients, without and with parenteral nutrition. Intensive Care Med 1988;14:212-6.

13. Aguilaniu B, Goldstein-Shapes S, Pajon A, et al. Muscle protein degradation in severely malnourished patients with chronic obstructive pulmonary disease subject to short-term total parenteral nutrition. JPEN J Parenter Enteral Nutr 1992;16:248-54.

14. Herskowitz K, Plumley DA, Martin TD, Hautamaki RD, Copeland EM, Souba WW. Lung glutamine flux following open heart surgery. J Surg Res 1991;51:82-6.

15. Svedjeholm R, Svensson S, Ekroth R, et al. Trauma metabolism and the heart: studies of heart and leg amino acid flux after cardiac surgery. Thorac Cardiovasc Surg 1990;38:1-5.

16. Svedjeholm R, Ekroth R, Joachimsson PO, Ronquist G, Svensson S, Tyden H. Myocardial uptake of amino acids and other substrates in relation to myocardial oxygen consumption four hours after cardiac operations. J Thorac Cardiovasc Surg 1991;101:688-94.

17. Svedjeholm R, Hakanson E, Vanhanen I. Rationale for metabolic support with amino acids and glucose-insulinpotassium (GIK) in cardiac surgery. Ann Thorac Surg 1995; 59:S15-22.

18. Ratcliffe JM, Wyse RKH, Hunter S, Alberti KGMM, Elliott MJ. The role of the priming fluid in the metabolic response to cardiopulmonary bypass in children of less than $15 \mathrm{~kg}$ body weight undergoing open-heart surgery. Thorac Cardiovasc Surg 1988;36:65-74.

19. Anand KJ, Hansen DD, Hickey PR. Hormonal-metabolic stress responses in neonates undergoing cardiac surgery. Anesthesiology 1990;73:661-70.

20. Souba WW, Klimberg VS, Plumley DA, et al. The role of glutamine in maintaining a healthy gut and supporting the metabolic response to injury and infection. J Surg Res 1990;48:383-91.

21. Julia PL, Young HH, Buckberg GD, Kofsky ER, Bugyi HI. Studies of myocardial protection in the immature heart. IV. Improved tolerance of immature myocardium to hypoxia and ischemia by intravenous metabolic support. J Thorac Cardiovasc Surg 1990;101:23-32.

22. Lorente $\mathbf{J A}$, Landin L, De Pablo R, Renes E, Liste D. 1-Arginine pathway in the sepsis syndrome. Crit Care Med 1993;21:1287-95.

23. Hiramatsu T, Forbess JM, Miura T, Nomura F, Mayer JE. Additive effects of L-arginine infusion and leukocyte depletion on recovery after hypothermic ischemia in neonatal lamb hearts. J Thorac Cardiovasc Surg 1995;110:172-9.

24. Sumner E, Stark J. Postoperative care. In: Stark J, de Leval M, editors. Surgery for congenital heart defects. 2nd ed. Philadelphia: WB Saunders; 1994. p. 193-233.

25. Gebara BM, Gelmini M, Sarnaik A. Oxygen consumption, energy expenditure, and substrate utilization after cardiac surgery in children. Crit Care Med 1992;20:1550-4.

26. Skeie B, Askanazi J, Rothkopf MM, Rosenbaum SH, Kvetan $\mathrm{V}$, Thomashow B. Intravenous fat emulsions and lung function: a review. Crit Care Med 1988;16:183-94. 